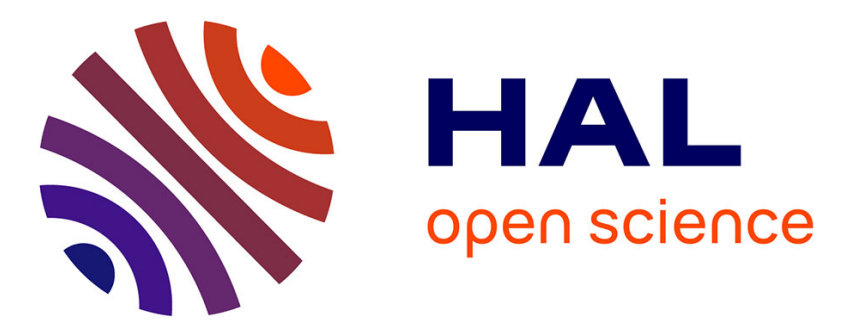

\title{
Digital twin of functional gating system in 3D printed molds for sand casting using a neural network
}

\author{
Ahmed Ktari, Mohamed El Mansori
}

\section{To cite this version:}

Ahmed Ktari, Mohamed El Mansori. Digital twin of functional gating system in 3D printed molds for sand casting using a neural network. Journal of Intelligent Manufacturing, In press, pp.1-13. 10.1007/s10845-020-01699-3 . hal-03159092

\section{HAL Id: hal-03159092 https://hal.science/hal-03159092}

Submitted on 8 Mar 2021

HAL is a multi-disciplinary open access archive for the deposit and dissemination of scientific research documents, whether they are published or not. The documents may come from teaching and research institutions in France or abroad, or from public or private research centers.
L'archive ouverte pluridisciplinaire HAL, est destinée au dépôt et à la diffusion de documents scientifiques de niveau recherche, publiés ou non, émanant des établissements d'enseignement et de recherche français ou étrangers, des laboratoires publics ou privés. 


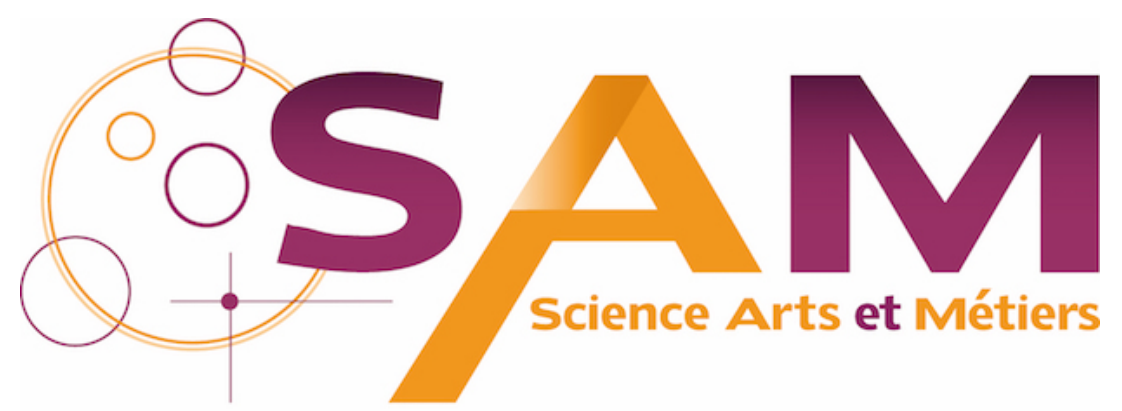

Archive Ouverte - Open Repository

\section{Science Arts \& Métiers (SAM)}

is an open access repository that collects the work of Arts et Métiers Institute of Technology researchers and makes it freely available over the web where possible.

This is an author-deposited version published in: https://sam.ensam.eu

Handle ID: .http://hdl.handle.net/10985/19931

\section{To cite this version :}

Ahmed KTARI, Mohamed EL MANSORI - Digital twin of functional gating system in 3D printed molds for sand casting using a neural network - Journal of Intelligent Manufacturing p.1-13 - 2020 


\title{
Digital twin of functional gating system in 3D printed molds for sand casting using a neural network
}

\author{
Ahmed Ktari ${ }^{1}$ (D) Mohamed El Mansori ${ }^{1,2}$
}

\begin{abstract}
The filling stage is a critical phenomenon in sand casting for making reliable castings. Latest research has demonstrated that for most liquid engineering alloys, the critical meniscus velocity of the melt at the ingate is in the range of $0.4-0.6 \mathrm{~m} \mathrm{~s}{ }^{-1}$. The work described in this research paper is to use neural network (NN) technology to propose digital twin approach for gating system design that allow to understand and model its performances faster and more reliable than traditional methods. This approach was applied in the case of sand casting of liquid aluminum alloy (EN AC-44200). The approach is based first on a digital representation of filling process to perform the melt flow simulations using a combination of the gating system design parameters, selected as a training cases from Taguchi orthogonal array (OA). The second step of the approach is the data capture of functional gating design system to train up the feed-forward back-propagation NN model. The validation of the well-trained NN model is assessed by interrogating predicted ingate velocity to it and making reliable predictions with high accuracy. The claim is that such digital twin approach is an effective solution to recognize the functional design parameters from the entire filling systems used during casting process.
\end{abstract}

Keywords Digital twin · Sand casting · Gating system design · FEM simulation · Neural Network

\section{Introduction}

Sand casting is an economical metal forming process that has been employed, since antiquity, to manufacture metal parts with a wide range of sizes and complexity. However, to have a good quality castings, several rules should be respected in the mold designs in particular the gating system since it permits to control the melt flow in the cavity. The transition from laminar to turbulent flow during the mold filling can lead to drastic effects on the quality of castings (Campbell 2015).

The filling process is typically comprised of free surface flow of the metal front inside the mold cavity. The exposure of liquid metals to air and moisture during free surface flows leads to the formation of surface oxide films (Gopalan and Prabhu 2011). Folding of free dry oxide surfaces result in

Ahmed Ktari

ahmed.ktari@ensam.eu

1 MSMP-EA7350, Arts et Métiers ParisTech, 2 Cours des Arts et Métiers, 13617 Aix-En-Provence, France

2 Department of Mechanical Engineering, Texas A\&M University, College Station, TX 77840, USA harmful double oxide films named bifilms (Campbell 2016; Raiszadeh and Griffiths 2006). Because these bifilms are necessarily folded on their dry sides during their creation, they act as cracks and initiate failure (Cao and Campbell 2003). The rate of bifilm formation increases with increase in turbulence as the oxide layers continuously stretch, rupture and regrow (Modaresi et al. 2017; Bakhtiarani and Raiszadeh 2011). Entrained defects as oxide inclusions, sand inclusions, blowholes, bubbles, bifilms among others are significantly detrimental to the castings mechanical properties (Basuny et al. 2016; Campbell 2015; Dai et al. 2004; Divandari and Campbell 2001). Hence, oxide films can affects tensile strength (Zhao et al. 2017; Mi et al. 2004; Sirrell and Campbell 1997), fracture strength (Green and Campbell 1994), fatigue life (Nyahumwa et al. 1998) and also act as initiation sites for shrinkage (Bangyikhan 2005) and hydrogen gas pore formation (Raiszadeh and Griffiths 2008) in castings. As a result, to reduce defects due to entrainment since they cause $80 \%$ of the total effective problems in castings (Bozchaloei et al. 2012), it is critical to design proper gating systems that permit to control the liquid metal flow during the mold filling phase by reducing the velocity at ingate to less than $0.5 \mathrm{~m} \mathrm{~s}^{-1}$ 
(Sama et al. 2019a, b; Campbell 1993; Runyoro et al. 1992). This will improve product quality and foundry productivity.

In the past, several researchers have experimented with various parameters to design straight sprue based on the basic principles of fluid dynamics. Most of the current design knowledge on gating systems are derived from trial and error approaches (Ruddle 1956), water modelling (Renukananda and Ravi 2016) and using computational simulation tools (Sama et al. 2019a; Nimbulkar and Dalu 2016). Since the kinematic viscosity of most liquid metals is similar to water (Renukananda and Ravi 2016; Swift et al. 1949), numerous researchers have experimented with water models using transparent molds usually made of Acrylic (Shaikh et al. 2018; Renukananda and Ravi 2016) to visualize in real time the fluid flow in molds (Juretzko and Stefanescu 2005). Newly, Sama et al. (2019b) have proposed a novel method of embedded Internet of Things (IoT) sensors to monitor realtime melt flow velocity in 3D sand printing mold during metal casting.

Nowadays, in view of the evolution of artificial intelligence (AI) tools, several authors have applied neural network (NN) to solve casting quality problems in production. In this context, Lin et al. (2019) have proposed a 3D convolutional neural network, a nonlinear topological dimension parameter and an empirical model for extracting the microstructural properties of casting defect regions efficiently. Mrzyglod et al. (2019) have proposed an intelligent computing tool based on NN and fuzzy logic that permit to forecast the microstructure of the tested cast iron at the level of computer simulation. These authors have shown the possibility to apply the Adaptive Neuro-Fuzzy Inference System (ANFIS) model as a tool to control the chemical composition of compacted graphite iron in the production of castings with high-strength parameters. Krimpenis et al. 2006 have proposed a methodology based on FEM and NN that permit to predict, using real-life data, a variety of pressure die-casting components, structured in terms of product geometric characteristics and corresponding process parameters value ranges. Further literature review (Ghosh et al. 2014; Zhang and Wang 2013; Vosniakos et al. 2009) shows that NN tools are relatively applied in the casting field to study and improve the castings product quality as a function of the process parameters.

The above discussion shows that various research have focused on trial and error experiment, FE methods and AI solutions for enhancing the casting process and improving the casting quality. However, most of the existing research is fragmented without a common vision towards a converging digital twin paradigm.

In this work, a digital twin of filling system is proposed, as a unifying paradigm, to use it for functional design and control of engineering gating systems in castings. The data would be measured using instrumented casting tests or collected based on numerical simulation of mold filling and fed directly into the trained NN quality control of functional gating design package. The NN package has been designed to perform a variety of tasks: $i$ ) Numerical characterisations of melt filling process for quality and casting process control. This would provide more detailed information as functions of gating system on surface melt turbulence, critical melt velocity, and liquid melt front in the mold cavity, etc. ii) Intradesign differentiation and classification. This involves signal to noise $(\mathrm{S} / \mathrm{N})$ ratio and analysis of variance (ANOVA) to analyse the effects and the contributions of the design parameters on the critical behaviour of melt filling process such as ingate velocity, surface turbulence, and iii) Feature identification of functional design: it is intended to enable users to decide on any features of interest to be modified in design of functional gating system using different parameters (feeder geometry, primitive 3D shapes of castings, casting modulus, filling direction, convection-induced damage).

\section{Digital twin: a new concept of gating system design in 3D printed molds for sand casting}

The interaction and convergence between physical and virtual world of manufacturing is getting more and more attention thanks to the advances of AI, IoT, big data, and other new generation information technologies. Besides, the digital twin paves a way for the cyber-physical integration of manufacturing, which is an important bottleneck to achieve smart manufacturing. Indeed, digital twin consist to create the virtual models for physical objects in the digital way to simulate their behaviours. The virtual models could understand the state of the physical entities through sensing data, to predict, estimate, and analyse the dynamic changes. While the physical objects would respond to the changes according to the optimized scheme from simulation (Redelinghuys et al. 2020; Tong et al. 2020; Mukherjee and DebRoy 2019).

The digital twin of functional gating system of $3 \mathrm{D}$ printed sand mold, presented in this paper, consists of a closed loop, which includes an hybrid mechanistic/NN model, big data, data classification/intra-design classification model and machine learning, as shown in Fig. 1. The functions of each of these units and how they may help in the production of high quality castings in a timely manner are discussed below.

The mechanistic models are frequently applied in the casting field to estimate generally, the metallurgical attributes such as the solidification morphology (Nastac 1999) and grain structure ( $\mathrm{Gu}$ et al. 2019), and to predict the micro/macro-scale defect formation such as shrinkage (Kwon 2019; Stefanescu 2005) based on well-established theories. Furthermore, these models can be applied to simulate the melt flow behaviour based on classical fluid dynamic equations and uses control volume-finite element to solve the momentum and energy equations to obtain solution for the 


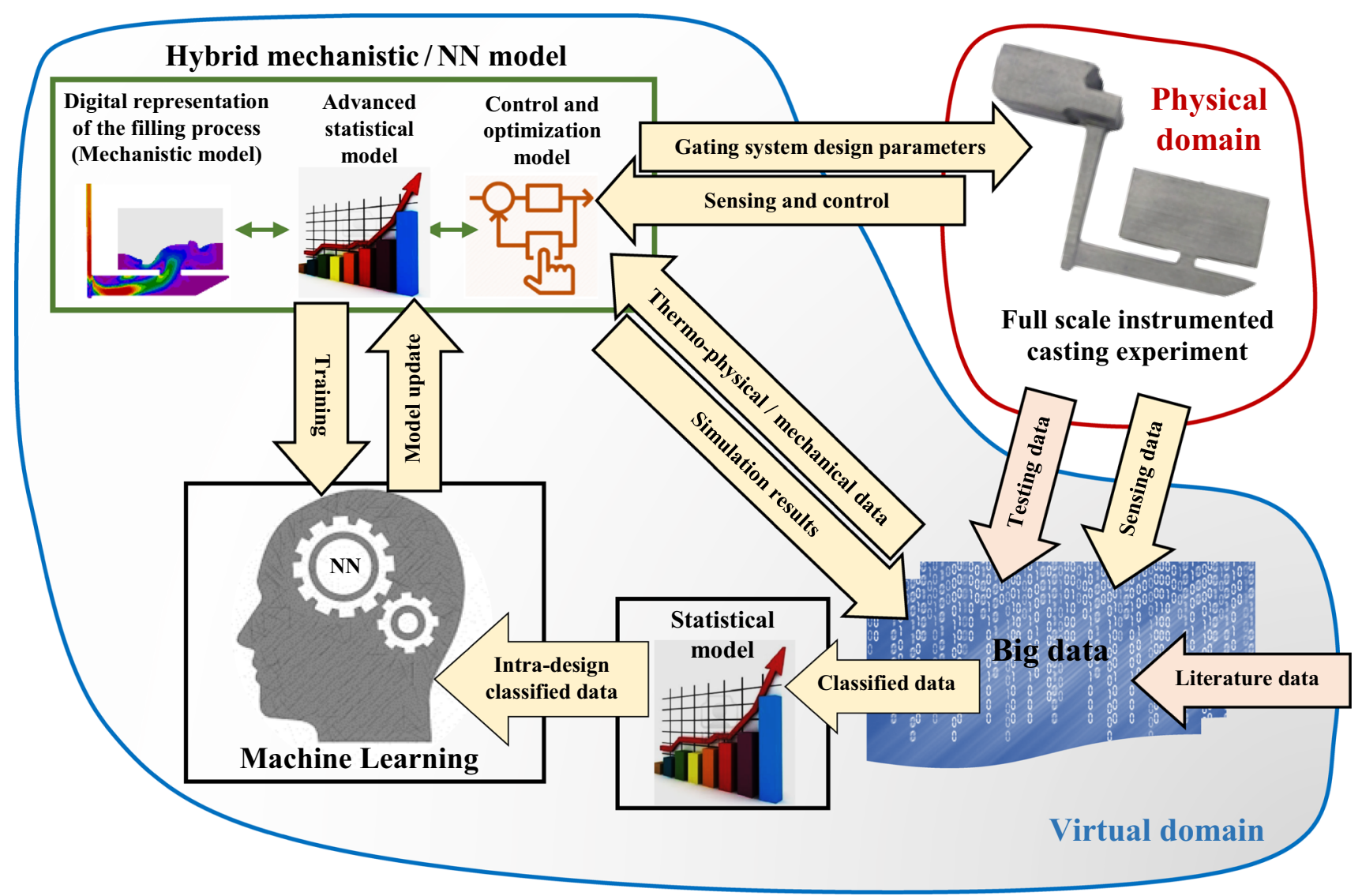

Fig. 1 Schematic representation of the digital twin of gating system functional design

variable parameters. In the proposed digital twin, the mechanistic model can be coupled with NN model as presented in Fig. 1. The hybrid mechanistic/NN model can be made bidirectional, so that they can switch between input and output variables. In other words, they can compute a set of functional gating system design parameters necessary to limit the flow velocity in molds, during the filling phase, less than $0.5 \mathrm{~m} \mathrm{~s}^{-1}$ to achieve desired casting properties (Sama et al. 2019a).

A sensing and control model could be interfaced during casting part with multiple sensors such capacitive or magnetic sensors used to measure the melt flow velocity in mold cavities (Sama et al. 2019b) and wireless sensors for temperature measurements at several deeps inside molds (Walker et al. 2018). These models can be used for online control of the filling process. During the filling phase, the model continuously assesses the sensing data to check if they are within the acceptable limits. If any deviation is found, the control model offers a new filling system design by adjusting its geometrical dimensions, to avoid for example a turbulent melt flow in the cavity.

Both mechanistic and control models are complex and their outputs may have errors due to several used assumptions in the FE model such errors in thermo-physical and thermomechanical properties data, errors caused by the spatial discretization of the FE method and the common numerical errors. In order to minimize theses errors, the mechanistic and the control models should be combined with advanced statistical models.

In sand casting process, many variables can affect the value of the ingate velocity during the filling phase and $\mathrm{FE}$ model predictions are not always in agreement with experimental data because the complexity of the melt flow in the mold cavity. As a result, the advanced statistical model can correct the inaccuracies of the FE model predictions based on previous results from a set of classified records within a large set of data known as the big data of casting.

The big data is a huge collection of variety of digital data that cannot be stored and analysed by usual resources. In the proposed digital twin, the big data for 3D printed molds for sand casting is independent from the data-capture techniques and can be divided in four main types of records as shown in Fig. 1. First, it contains the data obtained by sensing such as the melt and mold temperature, the melt velocity in the gate and features of liquid melt front in the mold cavity. Second, data from the test results of previously casted parts such as 
mechanical properties, which largely depends on melt filling conditions. Third, the computational results from valid FE model and finally, data can also be collected from literature.

The data must be appropriately used for continuous improvement of model prediction based, as mentioned above, on the data gathered from new experiment, simulations and growing literature. The data classification is performed in two steps. In the first one, the classification is based on the intended purpose using advanced algorithms (Qi and Tao 2018; Tao et al. 2018). Then, intra-design differentiation and classification is done in the second step (Huang and Ying 2019; Tsai and Luo 2017). This involves signal to noise (S/N) ratio and analysis of variance (ANOVA) to analyse the effects and the contributions of the design parameters on the critical behaviour of melt filling process such as ingate velocity and surface turbulence.

The expanding big data is used continuously to decide when and how to improve the model predictions using machine learning (LeCun et al. 2015). Machine learning provides dynamic ability to improve the control model based on continuously growing knowledge base and provides the digital twin the agility to change with time. The machine learning is achieved by implementing smart algorithm such NN (Sha and Edwards 2007) that can be developed in two steps starting by the training phase with a set appropriately data. Next, the trained neural network is tested and validated using additional set of data excluded during training.

In summary, the proposed digital twin concept of functional gating system, in 3D printed sand mold, is illustrated with more details through the following section on a case study.

\section{Digital twin for functional gating system in 3D printed molds for sand casting: a case study}

In this section, the digital twin approach for gating system design described above is applied on a simple case study example to understand and model its performances. The approach is based first on a digital representation of filling process to perform the melt flow simulations using a combination of the gating system design parameters, selected as training cases from Taguchi orthogonal array (OA).

\section{Design of experiment and FE problem modeling}

The process parameters influencing the cast quality are based on the gating system design, which include the dimensions of a conventional sprue, runner and gate. The relevant dimensions and design parameters of the model used in sand casting process is illustrated as shown in Fig. 2. The cast part and gating system geometry were adopted from Yang et al. (1998).
Table 1 Gating system parameters and levels used in experimental plan following Taguchi's standard $\mathrm{L}_{27}\left(3^{11}\right)$ orthogonal array

\begin{tabular}{lrrrrrrrrrrr}
\hline Training case & A & B & C & D & E & F & G & H & I & J & K \\
No. & & & & & & & & & & & \\
\hline 1 & 12 & 12 & 6 & 160 & 90 & 30 & 8 & 30 & 10 & 40 & 24 \\
2 & 12 & 12 & 6 & 160 & 110 & 50 & 9 & 40 & 15 & 50 & 32 \\
3 & 12 & 12 & 6 & 160 & 130 & 70 & 10 & 50 & 20 & 60 & 40 \\
4 & 12 & 15 & 8 & 200 & 90 & 30 & 8 & 40 & 15 & 50 & 40 \\
5 & 12 & 15 & 8 & 200 & 110 & 50 & 9 & 50 & 20 & 60 & 24 \\
6 & 12 & 15 & 8 & 200 & 130 & 70 & 10 & 30 & 10 & 40 & 32 \\
7 & 12 & 18 & 10 & 240 & 90 & 30 & 8 & 50 & 20 & 60 & 32 \\
8 & 12 & 18 & 10 & 240 & 110 & 50 & 9 & 30 & 10 & 40 & 40 \\
9 & 12 & 18 & 10 & 240 & 130 & 70 & 10 & 40 & 15 & 50 & 24 \\
10 & 16 & 12 & 8 & 240 & 90 & 50 & 10 & 30 & 15 & 60 & 24 \\
11 & 16 & 12 & 8 & 240 & 110 & 70 & 8 & 40 & 20 & 40 & 32 \\
12 & 16 & 12 & 8 & 240 & 130 & 30 & 9 & 50 & 10 & 50 & 40 \\
13 & 16 & 15 & 10 & 160 & 90 & 50 & 10 & 40 & 20 & 40 & 40 \\
14 & 16 & 15 & 10 & 160 & 110 & 70 & 8 & 50 & 10 & 50 & 24 \\
15 & 16 & 15 & 10 & 160 & 130 & 30 & 9 & 30 & 15 & 60 & 32 \\
16 & 16 & 18 & 6 & 200 & 90 & 50 & 10 & 50 & 10 & 50 & 32 \\
17 & 16 & 18 & 6 & 200 & 110 & 70 & 8 & 30 & 15 & 60 & 40 \\
18 & 16 & 18 & 6 & 200 & 130 & 30 & 9 & 40 & 20 & 40 & 24 \\
19 & 16 & 12 & 10 & 200 & 90 & 70 & 9 & 30 & 20 & 50 & 24 \\
20 & 20 & 12 & 10 & 200 & 110 & 30 & 10 & 40 & 10 & 60 & 32 \\
21 & 20 & 12 & 10 & 200 & 130 & 50 & 8 & 50 & 15 & 40 & 40 \\
22 & 20 & 15 & 6 & 240 & 90 & 70 & 9 & 40 & 10 & 60 & 40 \\
23 & 20 & 15 & 6 & 240 & 110 & 30 & 10 & 50 & 15 & 40 & 24 \\
24 & 20 & 15 & 6 & 240 & 130 & 50 & 8 & 30 & 20 & 50 & 32 \\
25 & 20 & 18 & 8 & 160 & 90 & 70 & 9 & 50 & 15 & 40 & 32 \\
26 & 20 & 18 & 8 & 160 & 110 & 30 & 10 & 30 & 20 & 50 & 40 \\
27 & 18 & 8 & 160 & 130 & 50 & 8 & 40 & 10 & 60 & 24 \\
\hline & & & & & & & & & & &
\end{tabular}

The advantage of the undercut at the base of pouring basin include minimizing the occurrence of splashing and the sprue cover prevents metal from directly falling into the sprue.

Given that Taguchi method requires a low number of experiment combinations, it can be applied to obtain useful information for reducing the number of experiments and converting quality characteristics into a signal to noise $(\mathrm{S} / \mathrm{N})$ ratio. Indeed, Taguchi orthogonal array is applied in this study to facilitate experimental design process as shown in Table 1 .

A coupled 3D thermo-hydraulic fluid flow modelling of the mold filling studied cases was performed via ProCAST ${ }^{\circledR}$ FE software with identical inlet, fluid and boundary conditions. Before calculation, some assumptions were made: (i) the liquid metal was incompressible Newton fluid, and (ii) the filling of molten metal is a non-isothermal flow accompanied by heat transfer losses. In the present study, the thermodynamic behaviour and flow field evolution are analysed via 

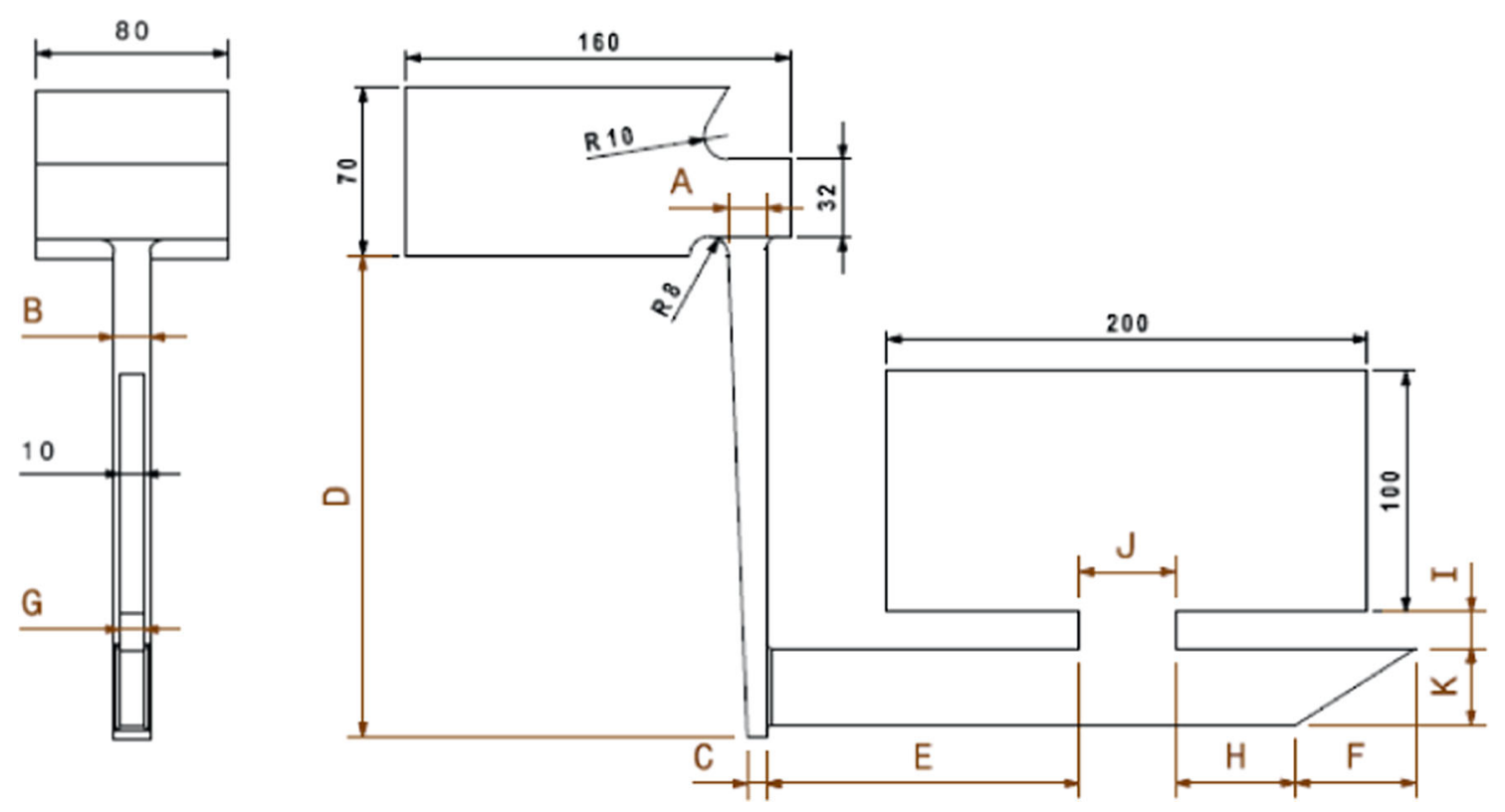

Fig. 2 Design and dimensions of the casted part with the studied gating system (in mm)

the mass, momentum and energy equations as follows (Jiaqi et al. 2012):

Continuity equation

$\nabla \cdot u=0$

Navier-Stokes (momentum) equation

$\rho\left(\frac{\partial u}{\partial t}+(u \cdot \nabla) u\right)=\nabla \cdot \mu\left[\nabla u+(\nabla u)^{T}\right]-\nabla P+\rho g$

Energy equation

$\rho c \frac{d T}{d t}=\nabla \cdot(k \nabla T)+\dot{Q}$

where $\rho$ is the density, $t$ is the time, $\mu$ is the dynamic viscosity, $P$ is the pressure, $g$ is the gravitational acceleration component, $u$ is the velocity vector, $T$ is the temperature, $k$ is the thermal conductivity, $c$ is the specific heat and $\dot{Q}$ is an internal power source. The conservation equations are solved numerically using a fully implicit time-stepping scheme and a standard FE formulation (Baoguang et al. 2010). Further details of the numerical model are given in the user manual of ProCast ${ }^{\circledR}$ (2009).

The VOF method (Swaminathan and Voller 1994) is used to compute the location and movement of the fluid front. An order parameter $(F)$ having a value of unity in the fluid and zero outside is used to track the free-surface position.

$$
\frac{\partial F}{\partial t}+(u \cdot \nabla) F=0
$$

This equation is coupled to the Navier-Stokes equations by defining the domain over which the latter are solved.

The coupled model was chosen to make numerical model as close as possible to experimental conditions and to ensure that all selected combinations of gating system design parameters allows a complete filling of the mold cavity (i.e. avoid misrun risk). The problem modelling need geometrical information of the CAD model including the part, the gating system, and the sand mold. Hence, all studied cases of solid CAD models are generated using CATIA ${ }^{\circledR}$ V5 software before being imported in ProCAST ${ }^{\circledR}$.

In this study, the FE model is meshed using linear tetrahedral elements with a mesh size of $1 \mathrm{~mm}$ and $3 \mathrm{~mm}$ respectively for the casting and the mold (Fig. 3). The mesh size is selected based on several mesh refinements study in order to achieve more accurate solutions (i.e. The dependence of the melt flow on the mesh size is investigated). It is to be noted that the number of elements in FE simulation is variable, with an average value of $2.3610^{6}$, since it depends on the mold training case as presented in Table 1 .

Aluminium alloy EN AC-44200 is used for the casted part. These alloys have a wide range of applications in automotive and aerospace industries due to their excellent castability, mechanical properties as well as good corrosion and wear resistance. Temperature dependent thermo-physical material properties for thermal conductivity, specific heat capacity and density are taken from ProCAST ${ }^{\circledR}$ database. An initial temperature of $750{ }^{\circ} \mathrm{C}$ is applied to the inlet, which represents the pouring temperature of the molten metal. An inlet metal flow rate of $225 \mathrm{~cm}^{3} . \mathrm{s}^{-1}$ into the pouring basin was maintained constant during the filling phase (Sama et al. 2019a). The 
Fig. $3 \mathrm{CAD}$ and FE mesh applied on the studied model

Fig. 4 The evolution of the ingate velocity $\left(\mathrm{m} \mathrm{s}^{-1}\right)$ versus filling time (s): Computational flow simulation of the training case no. 6
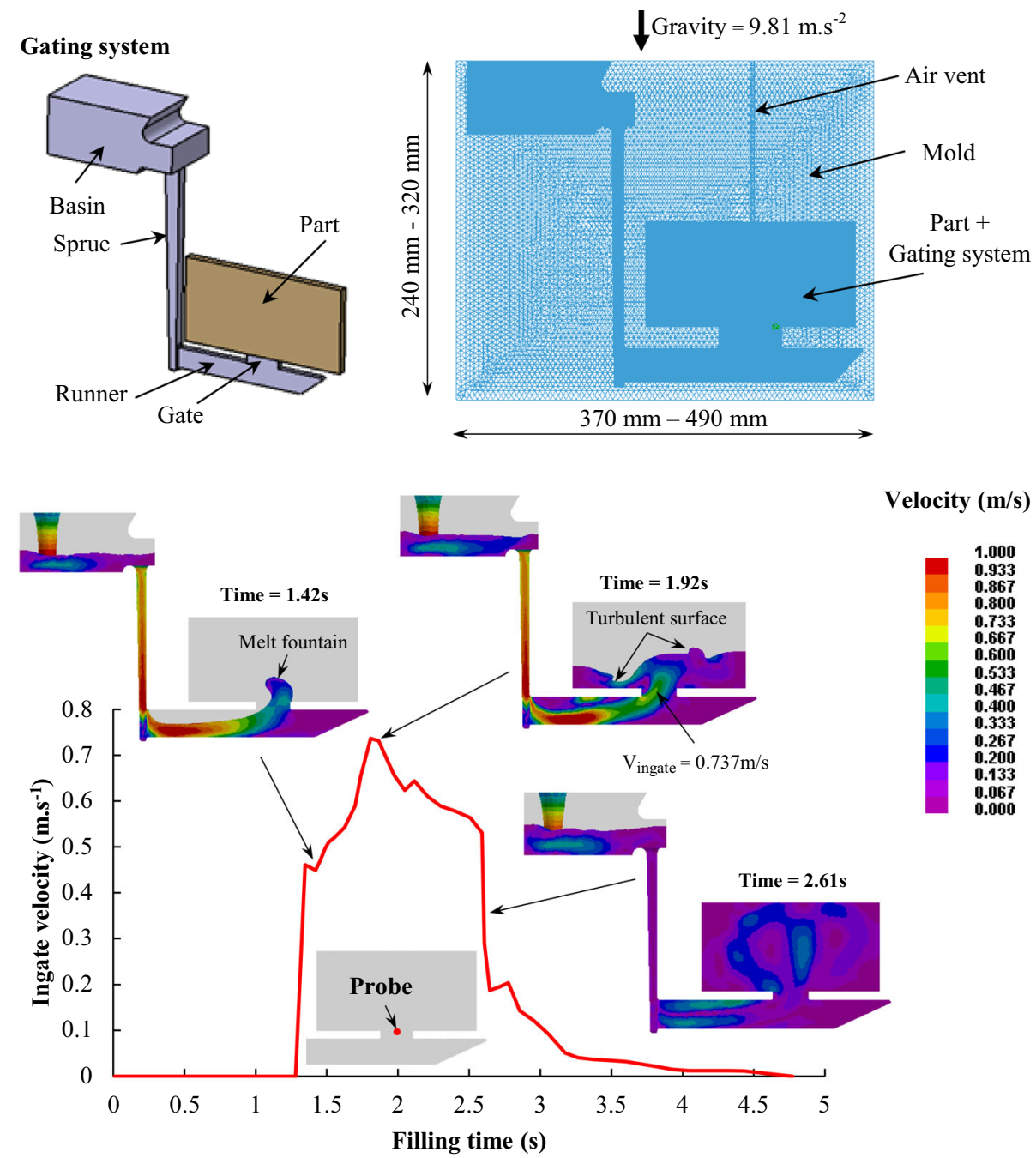

Velocity $(\mathbf{m} / \mathbf{s})$

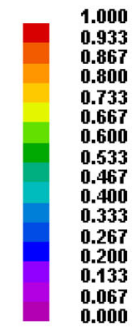

casting is cooled to room temperature in air with a convection coefficient of $10 \mathrm{~W} \cdot \mathrm{m}^{-2} \cdot{ }^{\circ} \mathrm{C}^{-1}$ applied to all six mold surfaces. The ambient (sink) temperature of the surrounding air is $25{ }^{\circ} \mathrm{C}$. In addition, a heat transfer coefficient of $350 \mathrm{~W} \cdot \mathrm{m}^{-2}$. ${ }^{\circ} \mathrm{C}^{-1}$ is applied at the metal/sand mold interface (Sun and Chao 2009).

With all the above setting of the trained FE models, the obtained results are consistent with actual flow patterns as revealed by radiography (Mi et al. 2004, Sirrell et al. 1996). This experimental validation denotes that the information obtained from the ProCAST ${ }^{\circledR}$ modeling can be used, with some confidence, as an important resource to enrich the big data. Finally, data set could be also analysed and then treated with traditional statistical techniques.

\section{Data analysis and classification}

The FE results must be appropriately analysed and treated to prepare the NN input design variables and their correspond- ing ingate velocity data. In this study case, the NN input data are only gathered from simulations results.

\section{Data analysis}

As shown in Fig. 4, Probes were placed at the end of the ingate along the mid-plane of the casting to monitor the evolution of the ingate velocity during the filling phase. It is clear that the molten metal arrives at the gate probe region after $1.28 \mathrm{~s}$ (Fig. 4). Then, the ingate velocity increase rapidly until attains a maximum velocity of $0.731 \mathrm{~m} \mathrm{~s}^{-1}$ at filling time value of $1.92 \mathrm{~s}$. Then, during the rest of the filling phase, the ingate velocity decreases slowly until the entire mold cavity filling marked by a sharp decrease of the ingate velocity $(\mathrm{t}=$ $2.58 \mathrm{~s}$ ). In addition, Fig. 4 also shows in the presented case, when the velocity of the liquid metal is higher than the critical value, that melt surface become unstable because of surface turbulence. In these conditions, the melt surface forms a fountain and a breaking wave that lead to the formation of several 
defects in the final casted part. This result entirety adheres to the critical ingate velocity condition described above.

The maximum value of the ingate velocity is selected for all training cases as revealed in Fig. 4 and then signal to noise ratios are calculated according to Taguchi method (Table 2). This method is considered as a quantitative analysis, largely used to identify control parameters that affect mean and variation of the quality characteristics. A high value of $\mathrm{S} / \mathrm{N}$ ratio indicates the optimum quality with minimum variation (Roy 2010). The S/N ratio, expressed in dB units, can be defined, as mentioned by Eq. (5), by logarithmic function based on the Mean Square Deviation (MSD) around target.

$S / N=-10 \log (M S D)$

where MSD is the mean square deviation for the output characteristic. The lower the better quality characteristic for the ingate velocity can be taken for obtaining the optimal casting quality. The MSD for the lower the better quality characteristic can be expressed as Eq. (6).

$M S D=\frac{1}{n} \sum_{i=1}^{n} Y_{i}^{2}$

where $n$ is a total number of tests in a trial and $Y_{\mathrm{i}}$ represents the value of the measured ingate velocity. This parameter is chosen due to its importance in the casting quality. In fact, decreasing of the ingate velocity can reduce turbulences and entrainment, which can lead to several casting defects (Campbell 1993, 2015).

\section{Intra-design gating system classification}

Based on the simulation results of the selected training cases (Table 2), the response of each factor to its individual level was calculated by averaging the $\mathrm{S} / \mathrm{N}$ ratios of all experiments at each level and factor (Fig. 5). After that, analyse of variance (ANOVA) test was performed to identify the most effective gating system parameters that significantly affect the filling ingate velocity. The ANOVA was established on the sum of the square (SS), the degree of freedom (DOF), the variance (V) and the percentage of the contribution to the total variation (Ross 1996). As shown in Table 3 at its confidence level of $90 \%\left(\mathrm{~F}_{0.1,2,26}=2.519\right)$, four design parameters (A, B, $\mathrm{C}, \mathrm{D}$ and $\mathrm{J}$ ) were found as significant for the ingate velocity. However, I is also considered as significant parameters for the gating system design, given that its F-ratio value is close to the acceptance value (difference less than 5.6\%).

In summary, the ANOVA result shows that gating system dimensions A, B, C, D, I and J play a crucial role on the value of the molten metal ingate velocity during the mold filling. Indeed, these six selected functional gating system design variables and their corresponding FEM simulated
Table 2 Ingate velocity and their corresponding $\mathrm{S} / \mathrm{N}$ ratio in orthogonal array

\begin{tabular}{llc}
\hline Training case no. & Ingate velocity ' $\mathrm{V}$ ' $(\mathrm{m} / \mathrm{s})$ & $\mathrm{S} / \mathrm{N}$ ratio ' $\mathrm{V}$ ' $(\mathrm{dB})$ \\
\hline 1 & 0.586 & 4.642 \\
2 & 0.535 & 5.433 \\
3 & 0.416 & 7.618 \\
4 & 0.672 & 3.453 \\
5 & 0.579 & 4.746 \\
6 & 0.737 & 2.651 \\
7 & 0.769 & 2.281 \\
8 & 1.070 & 0.587 \\
9 & 0.829 & 1.629 \\
10 & 0.543 & 5.304 \\
11 & 0.791 & 2.036 \\
12 & 0.875 & 1.160 \\
13 & 0.744 & 2.569 \\
14 & 0.856 & 1.351 \\
15 & 0.770 & 2.270 \\
16 & 0.717 & 2.890 \\
17 & 0.744 & 2.569 \\
18 & 0.745 & 2.557 \\
19 & 0.602 & 4.408 \\
20 & 0.693 & 3.185 \\
21 & 0.842 & 1.494 \\
22 & 0.820 & 1.724 \\
23 & 0.880 & 1.110 \\
24 & 0.795 & 1.993 \\
25 & 1.090 & 0.748 \\
26 & 0.747 & 2.534 \\
27 & 0.795 & 1.993 \\
\hline & & \\
& &
\end{tabular}

ingate velocity are used, respectively, as input/output data set for the NN learning process.

\section{Neural network for machine learning}

A neural network is a machine learning algorithm based on the model of a human neuron. The architecture of an artificial neural include usually up of three layers: an input layer, one or many hidden layers and an output layer. The neuron forms of the fundamental unit in the neural network, and each layer consists of one or many neurons. Each neuron is connected to other such neurons with synapses. Weight factors are allocated to these synapses which can be modified.

In this study, the $\mathrm{NN}$ was built and trained in $\mathrm{Matlab}^{\circledR}$ environment using Feed Forward Back Propagation (FFBP) neural network type (Daniel et al. 2019; Tsai and Luo 2017). A single hidden layer was selected. In order to find the optimal architecture, different numbers of neuron in the hidden layer were considered (the number of neuron in the hidden 


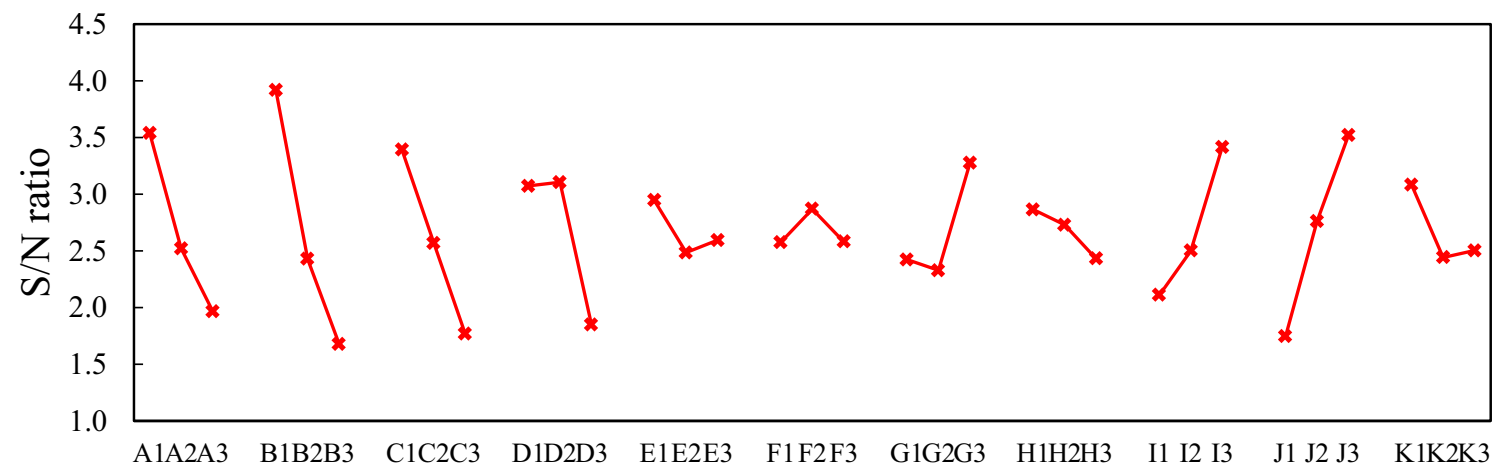

Fig. 5 Mean effect for $\mathrm{S} / \mathrm{N}$ ratios of the filling velocity at ingate

Table 3 ANOVA results for signal to noise for the ingate velocity response

\begin{tabular}{|c|c|c|c|c|c|c|c|}
\hline Gating parameters & Sum of square (SS) & $\begin{array}{l}\text { Degree of freedom } \\
\text { (DOF) }\end{array}$ & Variance $(\mathrm{V})$ & F-ratio & Contribution (\%) & Rank & $\begin{array}{l}\text { Significant } \\
(\text { confidence }>90 \%)\end{array}$ \\
\hline A & 12.032 & 2 & 6.016 & 4.094 & 14.155 & 2 & Yes \\
\hline $\mathrm{B}$ & 20.506 & 2 & 10.253 & 6.977 & 24.125 & 1 & Yes \\
\hline $\mathrm{C}$ & 10.578 & 2 & 5.289 & 3.599 & 12.445 & 4 & Yes \\
\hline $\mathrm{D}$ & 8.553 & 2 & 4.276 & 2.910 & 10.062 & 5 & Yes \\
\hline $\mathrm{E}$ & 1.266 & 2 & 0.633 & 0.431 & 1.489 & 9 & No \\
\hline $\mathrm{F}$ & 0.840 & 2 & 0.420 & 0.286 & 0.988 & 11 & No \\
\hline G & 4.076 & 2 & 2.038 & 1.387 & 4.796 & 7 & No \\
\hline $\mathrm{H}$ & 0.977 & 2 & 0.489 & 0.332 & 1.150 & 10 & No \\
\hline I & 6.983 & 2 & 3.492 & 2.376 & 8.216 & 6 & Yes $^{\mathrm{a}}$ \\
\hline $\mathrm{J}$ & 11.571 & 2 & 5.786 & 3.937 & 13.613 & 3 & Yes \\
\hline $\mathrm{K}$ & 1.739 & 2 & 0.870 & 0.592 & 2.046 & 8 & No \\
\hline Error & 5.878 & 4 & 1.470 & & 6.915 & & \\
\hline Total & 85.000 & 26 & & & 100 & & \\
\hline
\end{tabular}

${ }^{a}$ This parameter is considered as significant

layer was varied from 8 to 20) and RMSE for each network was calculated. In this study, the ability of the learning program to predict output response, using different parameters viz learning rate $\left(l_{r}\right)$ and momentum constant $\left(m_{c}\right)$ was also tested and optimized based on RMSE value (Eq. 7). The NN output with the lower RMSE value was identified as the best.

$R M S E=\sqrt{\frac{1}{n} \sum_{i=1}^{n}(P-E)^{2}}$

where $n$ is the total number of training case, $P$ and $E$ are the predicted and the experimental value respectively.

The learning rate parameter plays an important role for the learning algorithm. This parameter controls how much to change the model in response to the estimated error each time the model weights are updated. Choosing the learning rate is challenging because, large value causes rapid convergence but the algorithm becomes unstable that may cause the increase of error and very small values can yield a more
Table 4 The optimised NN parameters used to simulate the ingate velocity during sand mold filling

\begin{tabular}{ll}
\hline Parameter & Value \\
\hline Hidden layers & 1 \\
Neurons number & \\
Input layer (IL) & 6 \\
Hidden layer (HL) & 16 \\
Output layer (OL) & 1 \\
Transfer function & \\
HL & Logsig \\
OL & Purelin \\
Epoch size & 1000 \\
Momentum parameter $\left(m_{c}\right)$ & 0.2 \\
Learning rate $\left(l_{r}\right)$ & 0.01 \\
Ratio to increase $l_{r}$ & 1.05 \\
Ratio to decrease $l_{r}$ & 0.7 \\
\hline
\end{tabular}




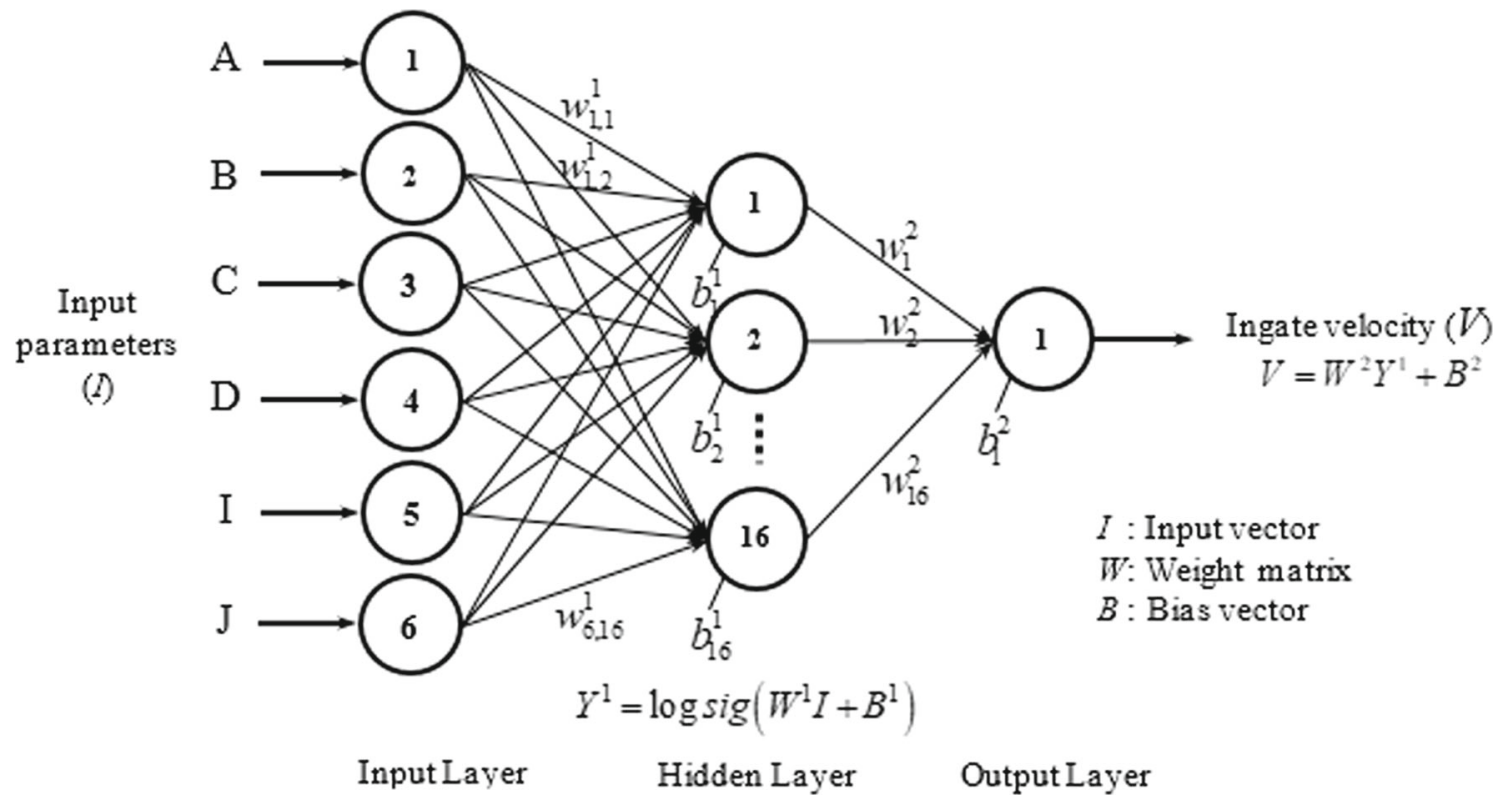

Fig. 6 Schematic representation of the back-propagation NN used for the prediction the ingate velocity during the sand mold filling

accuracy result, but longer time to converge (Brownlee 2019). The momentum constant is equally an important parameter that can affect learning algorithm. This parameter is used to prevent the system from converging to a local minimum or saddle point. A high momentum parameter can also help to increase the speed of convergence of the system. However, setting the momentum parameter too high can create a risk of overshooting the minimum, which can cause the system to become unstable. A momentum coefficient that is too low cannot reliably avoid local minima, and can slow down the system training. As a result, to ensure a relatively stable and fast algorithm convergence, a gradient descent with momentum and adaptive learning rate back propagation 'traingdx' was applied. This function can $i$ ) train any network as long as its weight, net input, and transfer functions have derivative functions, and ii) It calculates derivatives of performance (RMSE) with respect to the weight and bias variable $(X)$ (Martin et al. 2014). Each variable is adjusted according to gradient descent with momentum (Eq. 8).

$d X=m_{c} \cdot d X_{p r}+l_{r} \cdot m_{c} \cdot\left(\frac{\partial R M S E}{\partial X}\right)$

where $\mathrm{d} X_{p}$ presents the previous change in the weight or bias.

In the described model, random weights are assigned to each processing element as an arbitrary starting point in the training process, and then progressively modified in light of several repetition of training cases data. For the transfer function, the log-sigmoid 'logsig' function is used for all neurons in the hidden layer (Eq. 9). This transfer function takes the input (which may have any value between plus and minus infinity) and squashes the output into the range $0-1$. The log- sigmoid transfer function is commonly used in multilayer networks that are trained using the back propagation algorithm, in part because this function is differentiable (Dorofki et al. 2012).

$\log \operatorname{sig}(x)=1 /\left(1+\exp ^{-x}\right)$

The $\mathrm{NN}$ architecture and all its characteristic parameters are shown respectively in Fig. 6 and Table 4. A total data set of 27 gating system design parameter combinations was used to train the proposed NN. The data cases are divided in two subsets. The first subset is the training set $(80 \%$ of the total data), which is used for computing the gradient and updating the network weights and biases. The remaining five cases data (20\% of the total data) were used for validation.

The most common problem faced when training a neural network is the choice of the number of epochs. Too many epochs can lead to overfitting of the training dataset, while too few may result in an underfit model. In this work, the early stopping method is used in the $\mathrm{NN}$ training process. An epoch number of 1000 was specified as an arbitrary large number. The error on the validation set is monitored during the training process. The validation error decreases during the initial phase of training, as does the training set error. However, when the network begins to overfit the data, the error on the validation set typically begins to rise. The network weights and biases are saved at the minimum of the validation set error. This allows to obtain the optimal NN model with a complexity that achieves the optimal balance between bias and variance (Fortmann-Roe 2012). 
Table 5 Additional FE cases and their corresponding ingate velocity compared to NN predicted values

\begin{tabular}{|c|c|c|c|c|c|c|c|c|c|}
\hline \multirow[t]{2}{*}{ Validation FE cases } & \multicolumn{6}{|c|}{ Design parameters combination $^{\mathrm{a}}$} & \multicolumn{3}{|c|}{ Ingate velocity $(\mathrm{m} / \mathrm{s})$} \\
\hline & A & $\mathrm{B}$ & $\mathrm{C}$ & $\mathrm{D}$ & I & $\mathrm{J}$ & FEM & $\mathrm{NN}$ & Error $(\%)$ \\
\hline Case 28 & 13 & 17 & 10 & 230 & 14 & 45 & 0.908 & 0.926 & 1.98 \\
\hline Case 29 & 14 & 13 & 6 & 170 & 19 & 55 & 0.571 & 0.489 & 14.36 \\
\hline Case 30 & 19 & 18 & 7 & 210 & 16 & 60 & 0.872 & 0.882 & 1.15 \\
\hline Case 31 & 18 & 15 & 8 & 220 & 10 & 50 & 0.820 & 0.854 & 4.14 \\
\hline Case 32 & 12 & 14 & 9 & 160 & 12 & 40 & 0.703 & 0.692 & 1.56 \\
\hline \multirow[t]{2}{*}{ Case 33} & 20 & 16 & 8 & 180 & 18 & 48 & 0.724 & 0.696 & 3.87 \\
\hline & & & & & & & \multicolumn{3}{|c|}{ Average error: 4.51} \\
\hline
\end{tabular}

${ }^{\mathrm{a}}$ The rest of design parameters are maintained constant for the testing cases $(\mathrm{E}=110 ; \mathrm{F}=50 ; \mathrm{G}=9 ; \mathrm{H}=40$ and $\mathrm{K}=32)$

In this study, the optimised NN model, with sixteen neurons in the hidden layer has been tested with six additional cases to prove its generalisation capability as shown in Table 5. Indeed, the model is verified against randomly filling system design parameters simulated with FE code. This means that the additional testing data file is completely independent from the initial training data generated using Taguchi $\left(L_{27}\right)$ design of experiment. Figure 7 shows a plot of predicted NN versus FE ingate velocity for the training (train and validation) data used in the training process and the test data used for the $\mathrm{NN}$ generalization. A reasonable prediction occur in both cases. The RMSE for the prediction of the training and test data are respectively $0.045 \mathrm{~m} \mathrm{~s}^{-1}$ and $0.039 \mathrm{~m} \mathrm{~s}^{-1}$. This result proves that designed $\mathrm{NN}$ model gave a satisfactory approximation since it allowed the prediction of the ingate velocity for data not used in the learning process for the most testing data (except the case no. 29, in which the error percentage can reach the value of $14.36 \%$ ). proves that 27 training cases are sufficient in practice to turn on the digital twin. After the validation of the $\mathrm{NN}$ model, the predicted results are compared to the values of the ingate velocity using the first order response surface methodology (RSM) (i.e. calculated with Eq. 11 in Appendices). It is found that optimised NN model presents better data prediction compared to the traditional RSM model. The RMSE of the NN ingate velocity prediction is $0.045 \mathrm{~m} \mathrm{~s}^{-1}$ compared to 0.075 for RSM prediction (Fig. 7).

A digital twin is a high fidelity computational model that simulates known casting states. However, given the complex physics of casting process, digital twin is viewed here as a continuous learning using real casting experimental data. Experimental data are hence needed to calibrate the computational model as well as for updating parameters. The developed NN model is fed by data from casting part with embedded sensors (i.e. so called big data of casting collected from casting library of reference data). Indeed, the $\mathrm{NN}$ model was trained again taken into account the six additional FE simulations (Table 5) collected from the big data. Figure 8 shows the predicted results of the NN model before

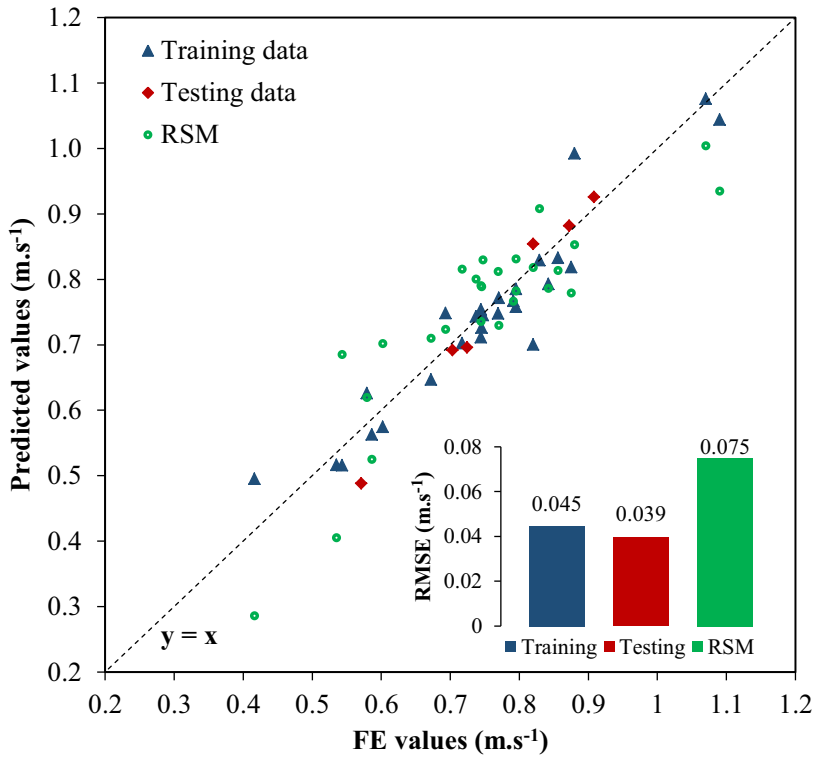

Fig. 7 FE simulated versus predicted ingate velocity for NN (training and testing data) and RSM models

and after the update process. The value of determination coefficient $\left(\mathrm{R}^{2}=0.956\right)$ indicates that the updated model does not explain only $4.4 \%$ of the total variations. However, this coefficient is about 0.912 for the first NN model. Furthermore, the RMSE of the updated NN prediction is $0.031 \mathrm{~m} \mathrm{~s}^{-1}$ compared to 0.044 for the first $\mathrm{NN}$ prediction. As a result, it is obvious that updated $\mathrm{NN}$ model presents better data prediction compared to the first model.

In summary, it is clear that optimized NN model can accurately predict the ingate velocity of a large number of functional gating system design variable combinations. These predictions can be carried on quite rapidly and easily compared to FE simulations. Finally, the found NN model can greatly reduce the simulation time devote to reach the optimal design parameters combination in the entirely studied design space. For this digital twin approach, the result predicted by the NN must be validated by FEM. If the result is consistent, the optimised design solution is accepted 


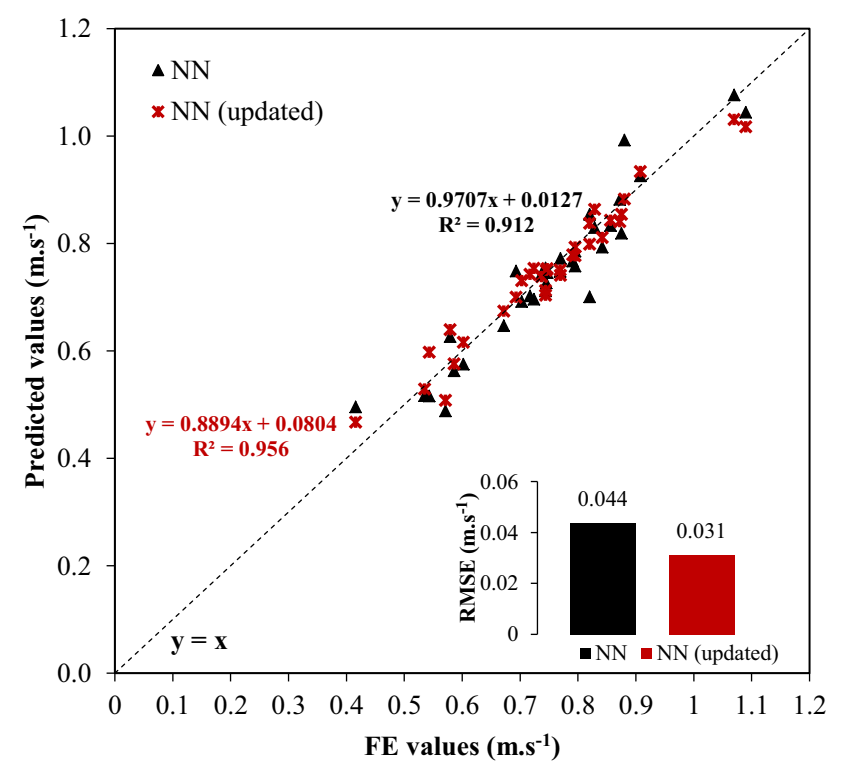

Fig. 8 FE simulated versus predicted ingate velocity before and after the NN model updating

for experimental casting. In addition, that FE model will became a training case for the $\mathrm{NN}$ in order to make it more knowledgeable, using a supervised machine learning. After updating the NN model, another functional gating system design solution can be suggested and validated by FEM again for continuous improvement of the NN model.

\section{Conclusion and outlook}

In today's highly competitive markets, the critical requirements for product quality, productivity and time to market have been become the most powerful driving force behind any new product development paradigm for seeking the best design solution and quality improvement. The current developments in digital technologies open up great possibilities for support designers to response to these new product design and development challenges through increased computing power, artificial intelligence tools, as wells as connected data.
Motivated by this need, the digital twins of functional gating system is proposed in this study as an artificial intelligence tool to allow an efficient prediction of the molten metal ingate velocity, in 3D printed molds for sand casting, in order to make the gating system design and optimization faster than traditional methods. To attain this objective, FE flow simulations were performed using a combination of the gating system design variables, selected as training cases from Taguchi OA. After that, an intra-design classification of the gating system parameters is achieved by the use of ANOVA tests to select the significant design variables on the ingate velocity. Finally, a NN model was trained and validated by using the set of significant design variables combination and their corresponding FE simulations. Then, machine learning allows the dynamic ability to improve the NN model based on a continuously growing of the knowledge base, and provides the digital twin the agility to change with time. This lead to obtain the desired product attributes and shorten the time to market and reduce the casting cost.

In future work, the main challenge is to define a consistent framework for the holistic use of the digital twin in entire 3D printed sand mold design issues in order to predict, control and optimize the design parameters for feeder geometry, primitive 3D shapes of castings, casting modulus, filling direction and convection-induced damage.

\section{Appendix}

The relationship between the selected gating design variables and their corresponding ingate velocity is described by the response surface methodology (RSM). A central composite design (CCD) with three level factorial design was employed in this study to construct an accurate RSM. Equation (10) shows the first-order regression model in RSM.

$Y=\beta_{0}+\sum_{j=1}^{m} \beta_{j} x_{j}+\sum_{j=1}^{m-1} \sum_{p=1}^{m} \beta_{j p} x_{j} x_{p}$

where $Y$ is the response objective, $x_{j}$ is the independent design variables and $x_{j} x_{p}$ is the interaction term. $\beta_{0}$ is the
Table 6 Factors and levels selected from ANOVA test

\begin{tabular}{|c|c|c|c|c|c|}
\hline \multicolumn{2}{|c|}{ Design parameters } & \multirow[t]{2}{*}{ Unit } & \multirow[t]{2}{*}{ Level - 1} & \multirow[t]{2}{*}{ Level 0} & \multirow[t]{2}{*}{ Level +1} \\
\hline & & & & & \\
\hline A & Top section Sprue width & $\mathrm{mm}$ & 12 & 16 & 20 \\
\hline B & Top section Sprue length & $\mathrm{mm}$ & 12 & 15 & 18 \\
\hline $\mathrm{C}$ & Bottom section Sprue width & $\mathrm{mm}$ & 6 & 8 & 10 \\
\hline $\mathrm{D}$ & Sprue higher & $\mathrm{mm}$ & 160 & 200 & 240 \\
\hline \multicolumn{6}{|c|}{ Gate } \\
\hline I & Ingate length & $\mathrm{mm}$ & 40 & 50 & 60 \\
\hline $\mathrm{J}$ & Runner higher & $\mathrm{mm}$ & 24 & 32 & 40 \\
\hline
\end{tabular}


constant term, $\beta_{j}$ is the $j$ th linear coefficient, and $\beta_{j p}$ is the $j p$ th interaction coefficient.

The six factors derived from the ANOVA results were used to construct the response objective. As shown in Table 6, the significant design variables three level CCD experiment, which are coded as -1 and +1 and the midpoint coded as 0 , was employed to determine the response surface model $V_{\text {ingate }}$ (Chen et al. 2016).

According to the first order regression equations (Eq. 3) the relationship between selected parameters and objective was established as shown in Eq. (11) after eliminating the insignificant terms.

$$
\begin{aligned}
V_{\text {ingate }}= & 0.75+0.04 \times \mathrm{A}+0.06 \times \mathrm{B}+0.035 \times \mathrm{C}+0.03 \times \mathrm{D} \\
& -0.036 \times \mathrm{I}-0.05 \times \mathrm{J}-0.024 \times \mathrm{AB}-0.055 \times \mathrm{AC} \\
& -0.047 \times \mathrm{AD}+0.017 \times \mathrm{AI}-0.024 \times \mathrm{BD}+0.024 \\
& \times \mathrm{CD}-0.012 \times \mathrm{CI}-0.006 \times \mathrm{DJ}-0.016 \times \mathrm{IJ}
\end{aligned}
$$

\section{References}

Bakhtiarani, F. N., \& Raiszadeh, R. (2011). Healing of double-oxide film defects in commercial purity aluminium melt. Metallurgical and Materials Transaction, 42(2), 331-340.

Bangyikhan, K. (2005). Effects of oxide film, Fe-rich phase, porosity and their interactions on tensile properties of cast $\mathrm{Al}-\mathrm{Si}-\mathrm{Mg}$ alloys. Ph.D. Thesis, University of Birmingham, School of Metallurgy and Materials.

Baoguang, S., Xiuhong, K., \& Dianzhong, L. (2010). A novel technique for reducing macrosegregation in heavy steel ingots. Journal of Materials Processing Technology, 210, 703-711.

Basuny, F. H., Ghazy, M., Kandeil, A. Y., \& El-Sayed, M. A. (2016). Effect of casting conditions on the fracture strength of Al-5Mg alloy castings. Advances in Materials Science and Engineering. https://doi.org/10.1155/2016/6496348.

Bozchaloei, G. E., Varahram, N., Davami, P., \& Kim, S. K. (2012). Effect of oxide bifilms on the mechanical properties of cast Al-7Si-0.3 Mg alloy and the roll of runner height after filter on their formation. Materials Science and Engineering A, 548, 99-105.

Brownlee, J. (2019). Better deep learning: Train faster, reduce overfitting, and make better, predictions machine. Vermont: Learning Mastery.

Campbell, J. (1993). Invisible macrodefects in castings. Journal de Physique IV, C7, 861-872. https://doi.org/10.1051/jp4:1993713 5.

Campbell, J. (2015). Complete casting handbook: Metal casting processes, metallurgy, techniques and design (2nd ed.). Oxford: Butterworth-Heinemann. ISBN 978-0-444-63509-9.

Campbell, J. (2016). The consolidation of metals: The origin of bifilms. Journal of Materials Science, 51(1), 96-106.

Cao, X., \& Campbell, J. (2003). The nucleation of Fe-rich phases on oxide films in $\mathrm{Al}-11.5 \mathrm{Si}-0.4 \mathrm{Mg}$ cast alloys. Metallurgical Materials Transaction A, 34(7), 1409-1420.

Cao, X., \& Campbell, J. (2005). Oxide inclusion defects in Al-Si-Mg cast alloys. Canadian Metallurgical Quarterly, 44(4), 435-448.

Chen, W. J., Lin, C. X., Chen, Y. T., \& Lin, J. R. (2016). Optimization design of a gating system for sand casting aluminium A356 using a Taguchi method and multi-objective culture-based QPSO algorithm. Advances in Mechanical Engineering, 8(4), 1-14.

Dai, X., Yang, X., Campbell, J., \& Wood, J. (2004). Influence of oxide film defects generated in filling on mechanical strength of aluminium alloy castings. Materials Science Technology, 20(4), 505-513.

Daniel, G., Kumar, G., \& Rizvi, A. U. H. (2019). Optimization of material removal rate in wire-EDM using Genetic Algorithm. International Journal of Applied Engineering Research, 14(1), 313-315.

Divandari, M., Campbell, J. (2001). Mechanisms of bubble damage in castings. Ph.D. Dissertation, University of Birmingham, the School of Metallurgy and Materials.

Dorofki, M., Elshafie, A., Jaafar, O., Karim, O., \& Mastura, S. (2012). Comparison of artificial neural network transfer functions abilities to simulate extreme runoff data. In International conference on environment, energy and biotechnology IPCBEE, vol. 33. Singapore: IACSIT Press.

Fortmann-Roe, S. (2012). Understanding the bias-variance tradeoff. Retrieved Oct 2020, from http://scott.fortmann-roe.com/docs/ Bias Variance.html.

Ghosh, I., Das, K. D., \& Chakraborty, N. (2014). An artificial neural network model to characterize porosity defects during solidification of A356 aluminum alloy. Neural Computing and Applications, 25(3-4), 653-662.

Gopalan, R., \& Prabhu, N. K. (2011). Oxide bifilms in aluminium alloy castings: A review. Materials Science Technology, 27(12), 1757-1769.

Green, N. R., \& Campbell, J. (1994). Influence of oxide film filling defects on the strength of Al-7Si-Mg alloy castings (94-114). Transaction of the American Foundrymens Society, 102, 341-348.

Gu, C., Lu, Y., Cinkilic, E., Miao, J., Klarner, A., Yan, X., et al. (2019). Predicting grain structure in high pressure die casting of aluminum alloys: A coupled cellular automaton and process model. Computational Materials Science, 15, 64-75.

Huang, C., \& Ying, K. (2019). Intelligent parametric design for a multiple-quality-characteristic glue-dispensing process. Journal of Intelligent Manufacturing, 30, 2291-2305.

Jiaqi, W., Paixian, F., Hongwei, L., Dianzhong, L., \& Yiyi, L. (2012). Shrinkage porosity criteria and optimized design of a 100-ton 30Cr2Ni4MoV forging ingot. Materials and Design, 35, 446-456.

Juretzko, F. R., \& Stefanescu, D. M. (2005). Comparison of mold filling simulation with high speed video recording of real-time mold filling. AFS Transactions, 113, 1-11.

Krimpenis, A., Benardos, P. G., Vosniakos, G. C., \& Koukouvitaki, A. (2006). Simulation-based selection of optimum pressure die-casting process parameters using neural nets and genetic algorithms. International Journal of Advanced Manufacturing and Technology, 27, 509-517.

LeCun, Y., Bengio, Y., \& Hinton, G. (2015). Deep learning. Nature, 521, 436-444.

Lin, J., Ma, L., \& Yao, Y. (2019). Segmentation of casting defect regions for the extraction of microstructural properties. Engineering Applications of Artificial Intelligence, 85, 150-163.

Majidi, S. H., Griffin, J., \& Beckermann, C. (2018). Simulation of air entrainment during mold filling: Comparison with water modeling experiments. Metallurgical and Materials Transaction B, 49(5), 2599-2610.

Martin, T., Demuth, H. B., Beale, M. H., \& De Jess, O. H. (2014). Neural network design (2nd edn). Texas, United States, ISBN 13:9780971732117.

Mi, J., Harding, R. A., \& Campbell, J. (2004). Effects of the entrained surface film on the reliability of castings. Metallurgical and Materials Transaction A, 35(9), 2893-2902.

Modaresi, A., Safikhani, A., Noohi, A. M. S., Hamidnezhad, N., \& Maki, S. M. (2017). Gating system design and simulation of gray 
iron casting to eliminate oxide layers caused by turbulence. International Journal of Metalcast, 11(2), 328-339.

Mrzyglod, B., Gumienny, G., Wilk-Kołodziejczyk, D., \& Regulski, K. (2019). Application of selected artificial intelligence methods in a system predicting the microstructure of compacted Graphite Iron. Journal of Materials Engineering and Performance, 28, 3894-3904.

Mukherjee, T., \& DebRoy, T. (2019). A digital twin for rapid qualification of 3D printed metallic components. Applied Materials Today, $14,59-65$.

Nastac, L. (1999). Numerical modeling of solidification morphologies and segregation patterns in cast dendritic alloys. Acta Materialia, 47, 4253-4262.

Nimbulkar, S. L., \& Dalu, R. S. (2016). Design optimization of gating and feeding system through simulation technique for sand casting of wear plate. Perspectives in Science, 8, 39-42.

Nyahumwa, C., Green, N. R., \& Campbell, J. (1998). Effect of mold-filling turbulence on fatigue properties of cast aluminium alloys (98-58). Transaction American Foundrymens Society, 106, 215-224.

ProCast User Manual Version 2009. (2009). 1. ESI group. The virtual try-out space company.

Qi, Q., \& Tao, F. (2018). Digital twin and big data towards smart manufacturing and industry 4.0: 360 degree comparison. IEEE Access, 6, 3585-3593.

Raiszadeh, R., \& Griffiths, W. D. (2006). A method to study the history of a double oxide film defect in liquid aluminium alloys. Metallurgical Materials Transaction B, 37(6), 865-871.

Raiszadeh, R., \& Griffiths, W. D. (2008). A semi-empirical mathematical model to estimate the duration of the atmosphere within a double oxide film defect in pure aluminium alloy. Metallurgical Materials Transaction B, 39(2), 298-303.

Redelinghuys, A. J. H., Basson, A. H., \& Kruger, K. (2020). A sixlayer architecture for the digital twin: A manufacturing case study implementation. Journal of Intelligent Manufacturing, 31, 1383-1402.

Renukananda, K. H., \& Ravi, B. (2016). Multi-gate systems in casting process: Comparative study of liquid metal and water flow. Materials and Manufacturing Processes, 31(8), 1091-1101.

Ross, P. J. (1996). Taguchi techniques for quality engineering: Loss function, orthogonal experiments, parameter and tolerance design (2nd ed.). New York: McGraw-Hill. ISBN 0070539588.

Roy, R. K. (2010). A primer on the Taguchi method (2nd ed.). Dearborn: Society of Manufacturing Engineers. ISBN 10: 0872638642.

Ruddle, R. W. (1956). The running and gating of Sand casting: A review of the literature, Monograph No. 19. London: Institute of Metal.

Runyoro, J., Boutorabi, S. M. A., \& Campbell, J. (1992). Critical gate velocity for film-forming casting alloys. A basis for process specification. Transaction of the American Foundrymens Society, 100, 225-234

Sama, S. R., Badamo, T., Lynch, P., \& Manogharan, G. (2019a). Novel sprue design in metal casting via $3 \mathrm{D}$ sand-printing. Additive Manufacturing, 25, 563-578.

Sama, S., MacDonald, E., Voigt, E., \& Manogharan, G. (2019b). Measurement of metal velocity in sand casting during mold filing. Metals, 9(10), 1079.

Sama, S. R., Wang, J., \& Manogharan, G. (2018). Non-conventional mold design for metal casting using 3D sand-printing. Journal of Manufacturing Processes, 34, 65-75.

Sha, W., \& Edwards, K. L. (2007). The use of artificial neural networks in materials science based research. Materials and Design, 28(6), $1747-1752$.
Shabani, M. O., \& Mazzahery, A. (2011). The ANN application in FEM modeling of mechanical properties of AL-Si alloy. Applied Mathematical Modelling, 35, 5707-5713.

Shaikh, M. B. N., Shazeb, A., Arfeen, K., \& Mohammed, A. (2018). Optimization of multi-gate systems in casting process: Experimental and simulation studies. IOP Conference Series: Materials Science and Engineering IOP Publishing, 404(1), 012040. https:// doi.org/10.1088/1757-899X/404/1/012040.

Sirrell, B., \& Campbell, J. (1997). Mechanism of filtration in reduction of casting defects due to surface turbulence during mold filling. AFS Transaction, 105, 645-654.

Sirrell, B., Holliday, M., \& Campbell, J. (1996). Benchmark testing the flow and solidification modeling of AI castings. JOM Journal of the Minerals Metals and Materials Society, 48(3), 20-23.

Stefanescu, D. M. (2005). Computer simulation of shrinkage related defects in metal castings: A review. International Journal of Cast Metals Research, 18(3), 129-143.

Sun, H. C., \& Chao, L. S. (2009). An investigation into the effective heat transfer coefficient in the casting of aluminium in a greensand mold. Materials Transactions, 50(6), 1396-1403.

Swaminathan, C. R., \& Voller, V. R. (1994). A time-implicit filling algorithm. Applied Mathematical Modelling, 18(2), 101-108.

Swift, R. E., Jackson, J. H., \& Eastwood, L. W. (1949). A study of principles of gating. AFS Transaction, 57, 76-88.

Tao, F., Cheng, J., Qi, Q., Zhang, M., Zhang, H., \& Sui, F. (2018). Digital twin-driven product design, manufacturing and service with big data. International Journal of Advanced Manufacturing Technology, 94, 3563-3576.

Tong, X., Liu, Q., Pi, S., et al. (2020). Real-time machining data application and service based on IMT digital twin. Journal of Intelligent Manufacturing, 31, 1113-1132.

Tsai, K., \& Luo, H. (2017). An inverse model for injection molding of optical lens using artificial neural network coupled with genetic algorithm. Journal of Intelligent Manufacturing, 28, 473-487.

Vosniakos, G. C., Galiotoua, V., Pantelisb, D., Benardosa, P., \& Pavloua, P. (2009). The scope of artificial neural network metamodels for precision casting process planning. Robotics and Computer-Integrated Manufacturing, 25, 909-916.

Walker, J., Harris, E., Lynagh, C., et al. (2018). 3D printed smart molds for sand casting. Inter Metalcast, 12, 785-796.

Yang, X., Din, T., \& Campbell, J. (1998). Liquid metal flow in moulds with offset sprue. International Journal of Cast Metals Research, 11(1), 1-12.

Zhang, L., \& Wang, R. (2013). An intelligent system for low-pressure die-cast process parameters optimization. International Journal of Advanced Manufacturing Technology, 65, 517-524.

Zhao, X. Y., Ning, Z. L., Cao, F. Y., Liu, S. G., Huang, Y. J., Liu, J. S., et al. (2017). Effect of double oxide film defects on mechanical properties of As-cast C95800 alloy. Acta Metall Sinica Eng. Lett., 30(6), 541-549.

Publisher's Note Springer Nature remains neutral with regard to jurisdictional claims in published maps and institutional affiliations. 